\title{
Evaluation of Pain Scale Decrease and Adverse Effects of Ketorolac Injections: An Observational Study in Patients with Postoperative Pain
}

\author{
Mawardi Ihsan ${ }^{1}$, Fivy Kurniawati ${ }^{1}$, Husna Khoirunnisa ${ }^{2}$, Belladonna Chairini ${ }^{2}$ \\ 1. Department of Pharmacology and Clinical Pharmacy, Universitas Gadjah Mada, Sekip Utara 55281 \\ Yogyakarta \\ 2. Undergraduate Program of Pharmacy, Universitas Gadjah Mada, Sekip Utara 55281 Yogyakarta
}

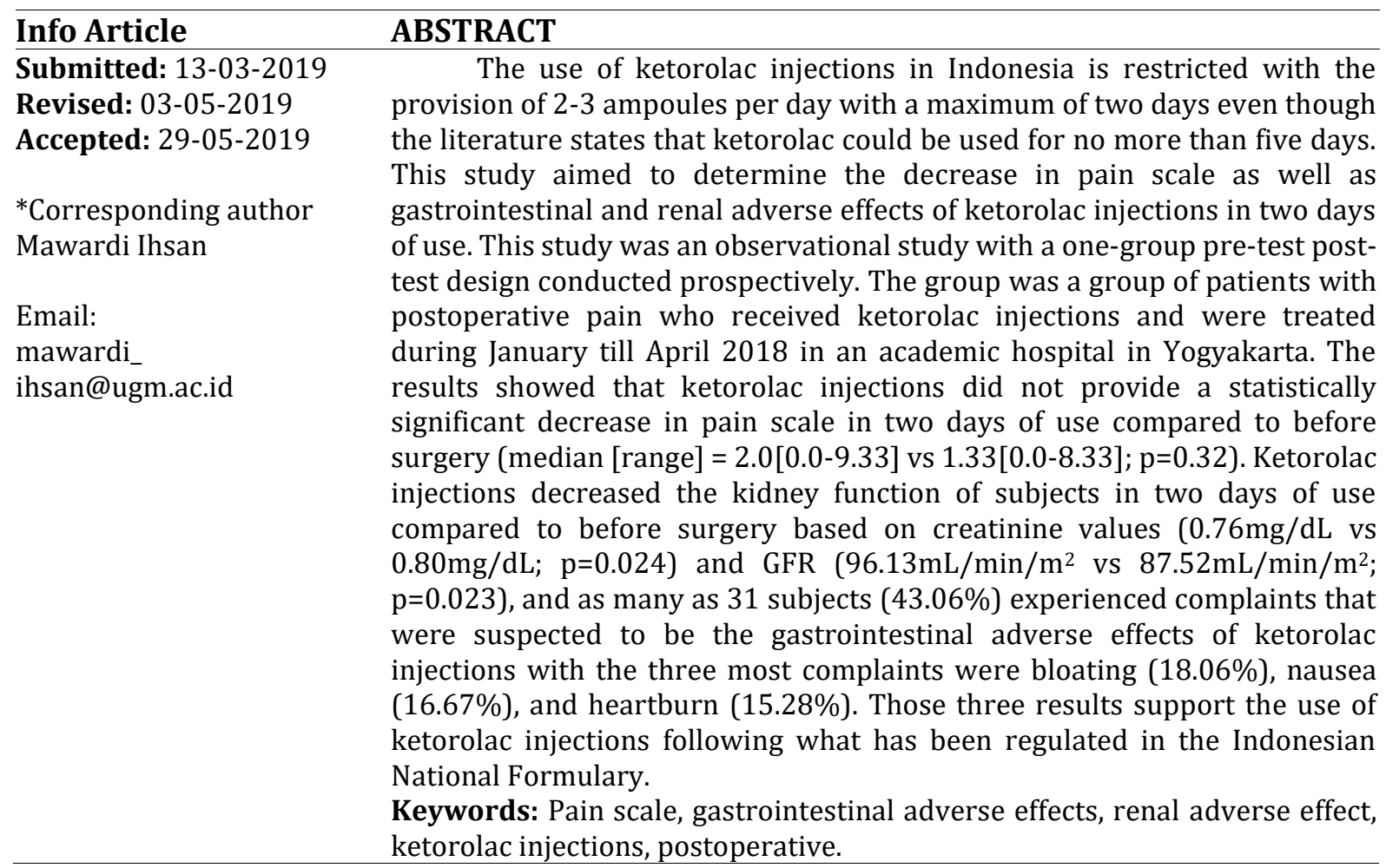

\section{INTRODUCTION}

Postoperative pain is an unexpected subjective complaint. Data on the prevalence of postoperative pain in Indonesia is still not well documented, but in other countries such as studies conducted in Barcelona, it had shown that the prevalence of orthopedic postoperative pain and trauma was around $28 \%$ with mild pain of $15 \%$ and moderate to severe pain by 13\% (Robleda et al., 2014). Another study showed that moderate to severe pain in the first $24 \mathrm{~h}$ and the first $48 \mathrm{~h}$ after surgery were $13 \%$ and $11.7 \%$, respectively (Mwaka et al., 2013). Ketorolac is one of the drugs of choice for postoperative pain management. A study showed that $89.7 \%$ of patients with postoperative pain in one hospital in Indonesia were treated using ketorolac (Permata, 2014).

The results of several other studies showed that ketorolac could provide better postoperative pain management than placebo, tramadol (Shah et al., 2013), diclofenac (Mony et al., 2016), and significantly reduced pain intensity 30 minutes after surgery (Eftekharian and Pak, 2017). However, the risk of gastrointestinal bleeding due to ketorolac was known to be quite high and relatively higher than other NSAIDs. The results of a study showed that nonselective NSAIDs increased the relative risk of bleeding, but ketorolac could increase the risk of bleeding much even higher (Gonza'lez et al., 2010). A study that examined the association between NSAIDs and chronic kidney disease (CKD) showed that ketorolac increased the risk of CKD by 2.54 times in less than 3 months (Ingrasciotta et al., 2015) and acute renal failure by 2.08 times if given for more than 5 days (Feldman et al., 1997). In addition, other studies that have been conducted showed that in addition to gastrointestinal bleeding, the 
adverse effects that may arise in 48 hours of ketorolac injections use in postoperative patients were; nausea/vomiting 37.5\%; dizziness $25 \%$; dyspepsia $8.7 \%$; pruritus $6.2 \%$; and constipation $3.1 \%$ (Siribumrungwong et al., 2015).

The use of ketorolac injections is generally restricted for no more than five days (Grosser et al., 2018; Strom et al., 1996), but the use of ketorolac injections in Indonesia is restricted with the provision of 2-3 ampoules per day with a maximum of two days by the Indonesian National Formulary (Kementerian Kesehatan, 2016). This certainly raises the question whether ketorolac influences the decrease in pain scale adequately and whether gastrointestinal and renal adverse effects will indeed appear in just two days. Therefore, this study aimed to determine the decrease in pain scale along with gastrointestinal and renal adverse effects of ketorolac injections in two days of use.

\section{MATERIAL AND METHODS Study design}

This study was an observational study with a one-group pre-test post-test design conducted prospectively. This study only consisted of one group, namely the group of patients who received ketorolac injections. The study was conducted in the surgical ward of an academic hospital in Yogyakarta since January till April 2018. The design of this study was approved by the Research Ethics Committee of the Faculty of Medicine (now is the Faculty of Medicine, Public Health, and Nursing) of the Universitas Gadjah Mada with number KE/FK/1033/EC/2017.

\section{Population and samples of study}

The population of this study was all surgical patients hospitalized in the surgical ward of the study hospital, while the study samples were all patients aged $\geq 18$ years with postoperative pain who received ketorolac injections during hospitalization in the surgical ward and were not included in the exclusion criteria specified in the study. The exclusion criteria of this study consisted: 1) Patients who were unconscious after completing surgery; 2) Patients with a history of peptic ulcer, chronic kidney disease, or were experiencing nausea, vomiting, diarrhea, and constipation before undergoing surgery.

\section{Data collection}

The collection of study subjects involved physicians who treated the patients and it was performed using consecutive sampling method. The physicians asked the patients to participate in the study by signing an informed consent sheet before undergoing surgery. After the patients agreed to participate as study subjects, the patients' pain scale was assessed using a numeric rating scale (NRS) instrument (Hawker et al., 2011) and determined as the baseline pain scale. The patients' pain scale was reassessed on the first and second day after surgery. Complaints or symptoms that were thought to be ketorolac adverse effects were monitored during treatment. Suspected adverse effects were adverse effects that lead to gastrointestinal and renal. Identification of gastrointestinal adverse effects of ketorolac injections use was performed using the Naranjo adverse drug reaction probability questionnaire (Belhekar et al., 2014), whereas the identification of renal adverse effects was carried out by examining the patients' serum creatinine and Blood Urea Nitrogen (BUN) values.

\section{Data analysis}

Numerical data were processed in decimal form with the central tendency of data in the form of mean \pm SEM (Standard Error of Mean) if the data is normally distributed statistically, or in the form of median if the data were not normally distributed. Patient data that were categorized were processed in the form of proportions. Both types of data were then presented in the form of tables or figures.

The analysis of decrease in pain scale was done by comparing the pain scale before surgery with the pain scale on the day one and day two after surgery, whereas the analysis of decrease in kidney function was done in two ways, namely by comparing creatinine values before undergoing surgery with creatinine values on day two after surgery, and by comparing values of GFR before undergoing surgery with GFR on day two after surgery. Measurement of the value of GFR was done using the MDRD4 formula (Levey et al., 2000). Before analyzing the decrease in the pain scale and kidney function, the investigators conducted a data distribution normality test using the Shapiro-Wilk test. Then, the significance of the decrease in pain scale and kidney function (creatinine and GFR) was tested using paired t-test if the data were normally distributed or the Wilcoxon test if the data were not normally distributed statistically. The $\mathrm{p}$-value of $<0.05$ showed that the pain scale or kidney function before undergoing surgery were significantly different from day one or two after surgery. 
Table I. Characteristics of study subjects

\begin{tabular}{|c|c|c|c|}
\hline \multicolumn{2}{|l|}{ Characteristics } & Mean $\bar{x} \pm \operatorname{SEM}(\mathrm{N}=72)$ & Proportion n (\%) (N=72) \\
\hline \multicolumn{2}{|l|}{ Age (years) } & $46.76 \pm 1.90$ & \\
\hline \multicolumn{2}{|c|}{ Baseline blood pressure (mmHg) } & $124.67 \pm 1.95 / 77.25 \pm 0.99$ & \\
\hline \multicolumn{2}{|c|}{ Baseline pain scale } & $2.13 \pm 0.28$ & \\
\hline \multicolumn{2}{|c|}{ Baseline BUN (mg/dL) $\left(\mathrm{N}=43^{\mathrm{a}}\right)$} & $25.70 \pm 1.57^{\mathrm{a}}$ & \\
\hline \multicolumn{2}{|c|}{ Baseline creatinine $(\mathrm{mg} / \mathrm{dL})\left(\mathrm{N}=43^{\mathrm{a}}\right)$} & $0.84 \pm 0.03^{\mathrm{a}}$ & \\
\hline \multicolumn{2}{|c|}{$\begin{array}{l}\text { Baseline GFR }\left(\mathrm{mL} / \mathrm{min} / 1.73 \mathrm{~m}^{2}\right) \\
\left(\mathrm{N}=43^{\mathrm{a}}\right)\end{array}$} & $95.34 \pm 3.39 \mathrm{a}$ & \\
\hline \multirow[t]{5}{*}{ Age groups } & $-19-35$ years & & $17(23.6)$ \\
\hline & $-36-45$ years & & $15(20.8)$ \\
\hline & $-46-60$ years & & $24(33.3)$ \\
\hline & $-61-75$ years & & $14(19.4)$ \\
\hline & $-76-90$ years & & $2(2.8)$ \\
\hline \multirow[t]{2}{*}{ Gender } & -Male & & $32(44.4)$ \\
\hline & -Female & & $40(55.6)$ \\
\hline \multirow[t]{2}{*}{ Smoking status } & -Yes & & $13(18.1)$ \\
\hline & -No & & $59(81.9)$ \\
\hline \multirow[t]{3}{*}{ Types of surgery } & -general surgery & & $32(44.44)$ \\
\hline & -digestive surgery & & $27(37.5)$ \\
\hline & -orthopedic surgery & & $13(18.1)$ \\
\hline \multirow[t]{4}{*}{ Comorbid } & -hypertension & & $11(15.28)$ \\
\hline & -diabetes & & $9(12.5)$ \\
\hline & -asthma & & $4(0.06)$ \\
\hline & -vertigo & & $2(0.03)$ \\
\hline \multirow[t]{2}{*}{ Ketorolac dose } & $-30 \mathrm{mg}$ every $8 \mathrm{~h}$ & & $70(97.2)$ \\
\hline & $-30 \mathrm{mg}$ every $12 \mathrm{~h}$ & & $2(2.8)$ \\
\hline
\end{tabular}

a=measured from only 43 patients who had complete BUN, creatinine, and GFR values on the day before undergoing surgery.

\section{RESULTS AND DISCUSSION}

This study aimed to: 1) to determine the adequacy of the decrease in the patients' pain scale given by injections of ketorolac on day one and day two after surgery, 2) to determine the effect of ketorolac injections on kidney function on day two after surgery, and 3) to investigate complaints suspected of being an adverse effect of ketorolac injections. This study was beneficial as a basis for evaluating the restrictions on the use of ketorolac injections according to the Indonesian National Formulary, which states that ketorolac injections are only given in a maximum of two days with a dose of 2-3 ampoules per day (Kementerian Kesehatan, 2016) even though Vadivelvu et al. (2017) states that ketorolac use may be used for not more than five days (Grosser et al., 2018; Vadivelu et al., 2017).

\section{Characteristics of study subjects}

The subjects of this study were surgical patients who were hospitalized and received ketorolac injections as a postoperative analgesic since February to April 2018 in the study site hospital. The types of surgery included in this study were general surgery, digestive surgery, and orthopedic surgery.

The subject collection was carried out by a consecutive sampling method and this study finally obtained a total of 72 patients. In general, the characteristics of the subjects in this study were general surgical patients aged 46-60 years with a mean age of $46.76 \pm 1.90$ years, female gender, not smoking, with comorbid of hypertension and received ketorolac injection dose of $30 \mathrm{mg}$ every $8 \mathrm{~h}$ during treatment (Table I). Also, the study subjects admitted the hospital with a pain scale of $2.13 \pm 0.28$ and normal kidney function which was seen through normal BUN, creatinine, and GFR values.

\section{The decrease in pain scale}

This study was conducted with a one group pre-test post-test design so that the statistically 


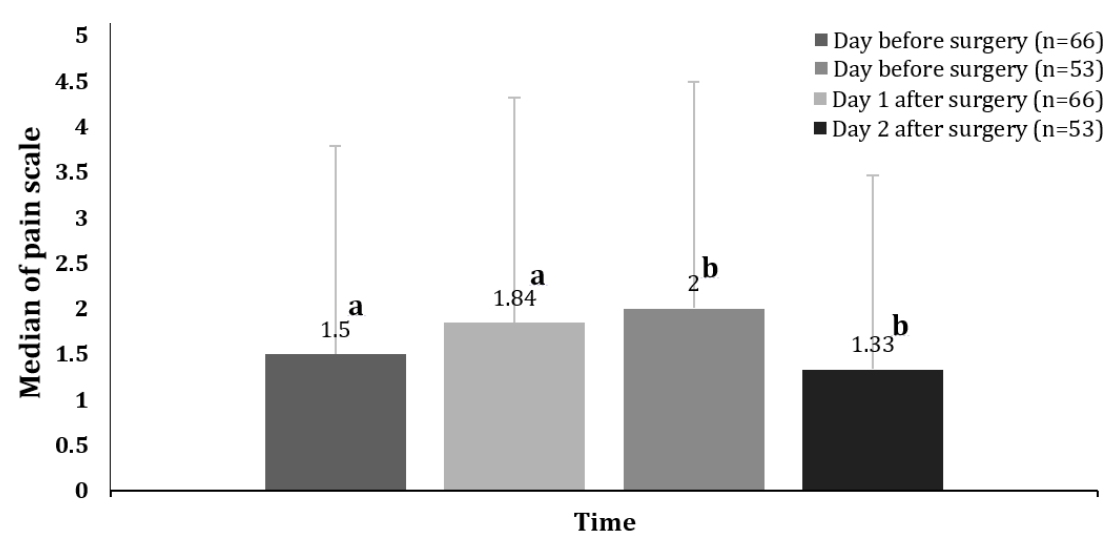

Figure 1. Median of pain scale from the day before surgery until day two after surgery. a=not significantly different with a $\mathrm{Z}$ score of -1.02 between before the surgery and the day one after surgery $(p=0.31) . b=n o t$ significantly different from the $\mathrm{Z}$ score of -0.994 before the surgery and day two after surgery $(\mathrm{p}=0.32)$.

tested data were only the completely paired data. This caused the number of subjects analyzed on the comparison of pain scale on the day before surgery with the day one after surgery was not the same as in the analysis on the comparison of the pain scale on the day before surgery with the day two after surgery.

Ketorolac injections did not decrease the pain scale on day one after surgery but were able to decrease the pain scale on day two after surgery (Figure 1). However, the decrease in the pain scale on day two after surgery produced by ketorolac injection was not significant. This indicated that the problem of postoperative pain was still unresolved using ketorolac injections as is presented in the pain management guidelines published by the American Pain Society (2016) which states that less than half of patients with postoperative pain report adequate postoperative pain relief (Chou et al., 2016).

A similar study was conducted by Eftekharian and Pak (2017) in which the study investigated the effects of intravenous ketorolac on postoperative pain in patients with mandibular fractures, but the pain measured was early postoperative pain. One study showed that ketorolac did not provide a pain scale that was different significantly with the placebo group in the first $4 \mathrm{~h}$ after surgery (pain intensity $1.08 \pm 0.49$ vs 1.04 $\pm 0.68 ; \mathrm{p}=0.135$; scores on Visual Analog Scale (VAS) $>1=16 \%$ compared to $24 \%, p=0.725$ ) (Eftekharian and Pak, 2017). There is still no agreement of opinion in the definition of relieving or control of pain although O'neil (2016) states that one example of pain management in patients with acute pain is pain with a scale of less than 3 (O'Neil, 2016).

\section{The decrease in renal function}

The study subjects included in the analysis of the decrease in kidney function in this study were subjects with complete creatinine level data before undergoing surgery and on day two after surgery so that the number of subjects analyzed amounted to only 23 patients. This study analyzed the decline in kidney function of the study subjects using serum creatinine and GFR parameters.

The results showed that ketorolac injections caused an increase in serum creatinine levels on day two after surgery (Figure 2). Although the increase in the value was slight $(0.4 \mathrm{mg} / \mathrm{dL})$, the results of statistical tests showed that the increase in the value was statistically significant. The GFR parameter was used to ensure that changes in kidney function occur because creatinine is a less specific parameter of kidney function. Creatinine is the end-product of nitrogen metabolism which is excreted in the urine. Creatinine production reflects total body muscle mass (Rae et al., 2018) so that the same creatinine levels among subjects could show different kidney function due to different muscle mass in different ages and genders.

Therefore, this study used GFR which is a more specific kidney function parameter. The results of the study also showed that the decline in kidney function in the subjects of the study consistently occurred when viewed using the GFR parameter (Figure 3). 


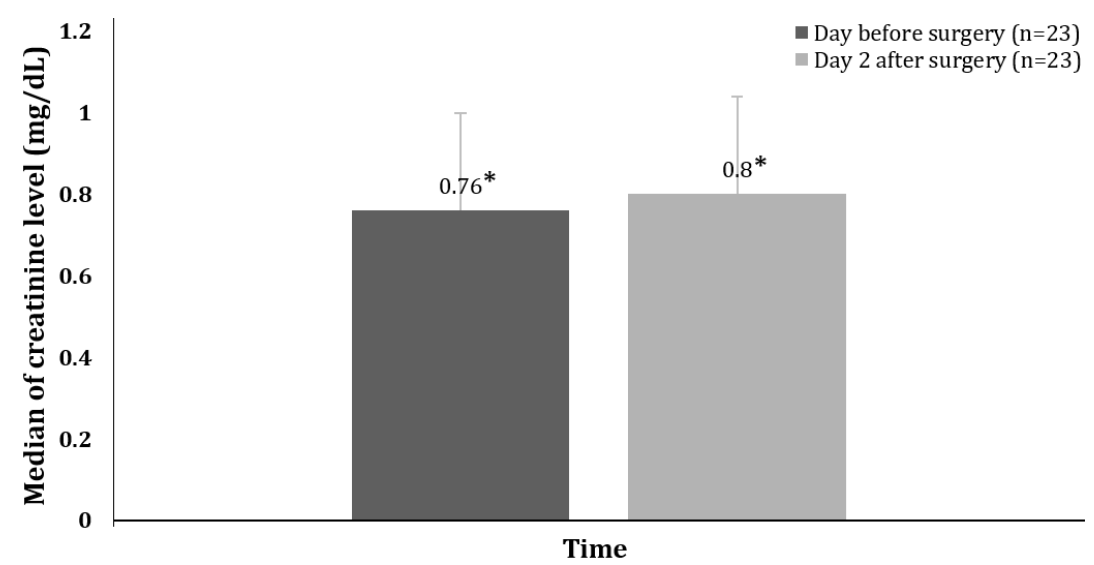

Figure 2. Median serum creatinine value from the day before undergoing surgery and day two after surgery. The study subjects included in this analysis of the increase in creatinine serum value were subjects with complete creatinine level data before surgery and on day two after surgery $(n=23)$ so that it was different with the number of subjects in the table of study subjects' characteristics ( $n=43)$ (Table I). Therefore, the serum creatinine value between this figure 2 and table I was also different. *=Statistically significant difference with a $\mathrm{Z}$ score of -2.25 of creatinine levels before undergoing surgery with day two after surgery $(\mathrm{p}=0.024)$.

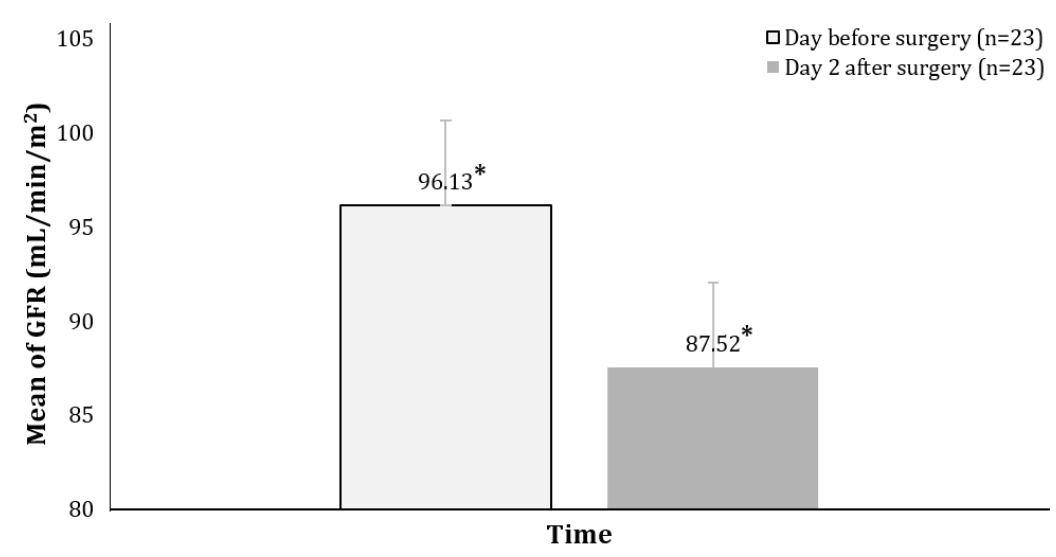

Figure 3. Mean GFR from days before undergoing surgery and day two after surgery. The number of study subjects included in this analysis of the decrease in GFR value $(n=23)$ was different with the number of subjects in the table of study subjects' characteristics $(n=43)$ (Table I) because the subjects were subjects with complete creatinine level data before surgery and on day two after surgery. Therefore, the GFR value between this figure and table I was also different. *=statistically significant with a difference in the mean GFR of $8.61 \pm 3.51 \mathrm{~mL} / \mathrm{min} / 1.73 \mathrm{~m}^{2}$ compared to the GFR value on the day before surgery $(\mathrm{p}=0.023)$.

Authors found that it is difficult to find relatively new studies of ketorolac, but because ketorolac is a drug belonging to the group of Nonsteroidal Anti-inflammatory Drugs (NSAIDs) (Candido et al., 2017) and because studies of NSAIDs generally included various types of NSAIDs including ketorolac, then a discussion of NSAID adverse effects on the kidneys could apply to ketorolac. Candido et al. (2017) mentioned that NSAIDs only caused a temporary mild decrease in kidney function on day one after surgery. The decrease was measured using creatinine clearance parameters in 1,450 healthy adults with a yield of $16 \mathrm{~mL} / \mathrm{min}$ [5-28 $\mathrm{mL} / \mathrm{min}]$ which was not significant compared to the placebo group (Candido et al., 2017). A systematic review study conducted by Zhang et al. (2017) showed that patients who were exposed to NSAIDs had an increased risk of Acute Kidney Injury (AKI) (OR 1.73 [1.44-2.07]) (Zhang et al., 2017). 


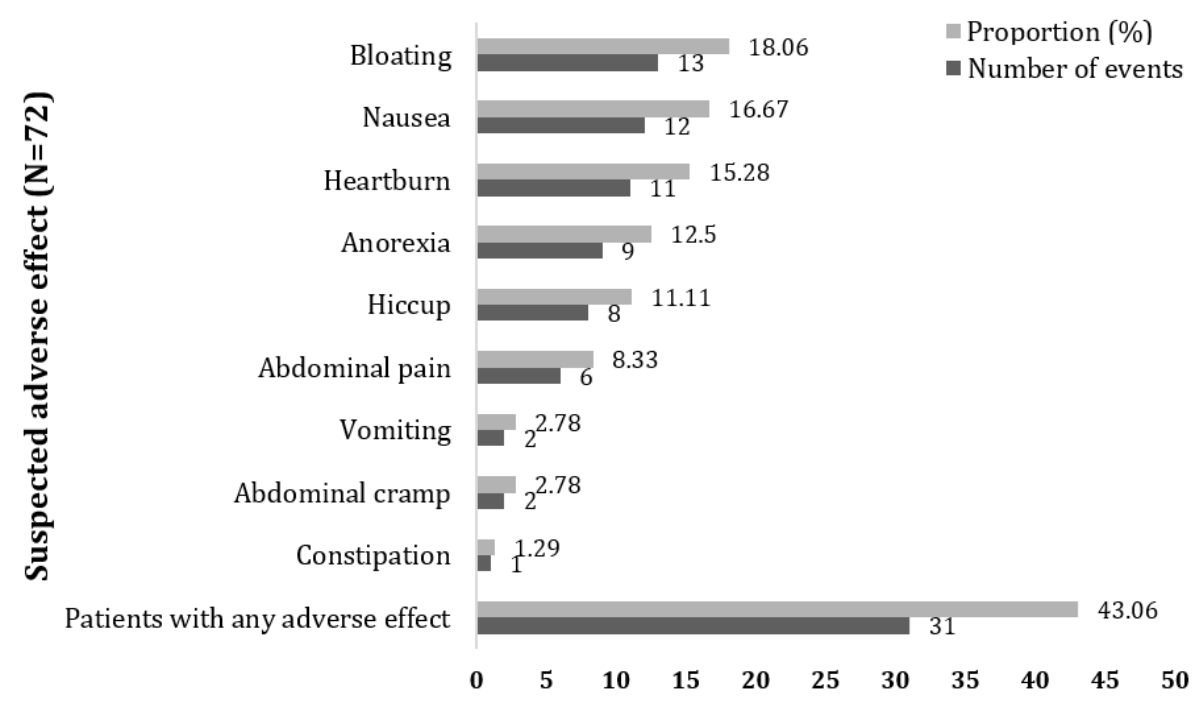

Figure 4. Events and proportions of each adverse effect suspected caused by ketorolac injections.

The results of the study are supported by a study conducted by Chou et al. (2016) whose results showed that the use of NSAIDs increased the risk of AKI COR 2.73 [2.28-3.28] in patients with current NSAID use and with OR 1.17 [1.01-1.35] in patients with NSAID use 30 days beforehand) (C.-I. Chou et al., 2016). NSAIDs do not only increase the risk of AKI but also End-Stage Renal Disease (ESRD) as in the results of a study conducted by Chang et al. (2015) (OR 2.72 [2.60-2.82]) (Chang et al., 2015).

Two mechanisms of NSAIDs-induced AKI in children have been estimated. Both mechanisms may also apply to cases of AKI induced by NSAIDs in adults. The two mechanisms are the mechanism of hemodynamic changes and Acute Interstitial Nephritis (AIN). The first mechanism causes around $78 \%$ of AKI cases to occur, while the second mechanism is around 22\% (Misurac et al., 2013). In the first mechanism, NSAIDs inhibit cyclooxygenase (COX) so that prostaglandin synthesis is inhibited. Prostaglandin acts as a vasodilation regulator that maintains adequate renal perfusion. The inhibition of prostaglandin synthesis causes uncontrolled vasoconstriction in afferent arterioles so that GFR decreases and causes acute ischemia and acute tubular necrosis. The AKI case in the second mechanism is also caused by NSAIDs which also inhibit COX, but the effect of this is the shift in arachidonic acid metabolism towards the pathway that synthesizes more leukotrienes, whereas leukotrienes are involved in the activation of the inflammatory response (Faught et al., 2015).

\section{Complaints which suspected as adverse effects of ketorolac injections}

The two instruments generally used to measure adverse effects are Naranjo and the WHOUMC scale (Belhekar et al., 2014), but the measurement of adverse effects in this study used a questionnaire developed by Naranjo. This questionnaire uses a scoring system that is divided into five probability categories consisting of definite, probable, possible and doubtful. Most of the complaints issued as the adverse effects of ketorolac injections in this study were categorized as probable category with a score of 5-8 (max. 13).

The results showed that the most and least common adverse effects of ketorolac injections were bloating (18.06\%) and constipation (1.29\%) (Figure 4). The overall incidence of complaints suspected of being an adverse effect of ketorolac injections was high because complaints occurred in almost half of the study subjects (43.06\%). The results of this study were slightly different from the results of a study conducted by Siribumrungwong et al. (2015) which, in that study the most common ketorolac adverse effects were nausea/vomiting (37.5\%), while the least was constipation (3.1\%) (Siribumrungwong et al., 2015). However, in this study, nausea was the second most common complaint suspected as an adverse effect of ketorolac injections with a proportion of $16.67 \%$. 
Another important adverse effect to note was that ketorolac could increase the risk of gastrointestinal bleeding the highest compared to other NSAIDs (OR 14.54 [5.87-36.04]) (Gonza'lez et al., 2010) based on adverse effect conducted by Gonzalez et al. (2010).

This study certainly had limitations. This study was an observational study that did not provide intervention to study subjects such as temporary stopping the ketorolac injections and re-challenging it after being stopped so that the measurement of the adverse effects of ketorolac injections in this study did not produce adverse effects that could reach definite degree. Complaints with probable degree still leave the possibility that the complaint was not due to ketorolac injections, but due to other factors such as patient comorbidities so that further studies with the interventional design conducted prospectively could improve the results of this study.

\section{CONCLUSION}

The conclusion that could be drawn from the results and discussion of this study is that two days of ketorolac injections use was not able to significantly decrease the postoperative pain scale statistically. Also, gastrointestinal adverse effects occurred with the two most common forms of bloating and nausea. The study also showed that the use of ketorolac injections for two days decreased kidney function as seen from an increase in serum creatinine levels and a decrease in GFR in the study subjects. Those three things can be the basis for consideration of the use of ketorolac injections for only two days following as regulated in the Indonesian National Formulary.

\section{ACKNOWLEDGMENT}

The authors say thank you to Agung Widianto, Adam Moeljono, and Wahyu Kartiko Tomo as the physicians who helped investigators to collect the study subjects. The authors also say thank you to Partini and the other nurses who practiced on the surgical ward of study site who had helped in taking blood samples from the study subjects.

\section{REFERENCES}

Belhekar MN., Taur SR. and Munshi RP., 2014. A study of agreement between the Naranjo algorithm and WHO-UMC criteria for causality assessment of adverse drug reactions. Indian J. Pharmacol. 46, 117.

Candido K.., Perozo OJ. and Knezevic NN., 2017.
Pharmacology of Acetaminophen, Nonsteroidal Antiinflammatory Drugs, and Steroid Medications: Implications for Anesthesia or Unique Associated Risks. Anesthesiol. Clin. 35, e145-e162.

Chang Y-K., Liu J-S., Hsu Y-H., Tarng D-C., and Hsu C-C., 2015. Increased Risk of End-Stage Renal Disease (ESRD) Requiring Chronic Dialysis is Associated With Use of Nonsteroidal. Medicine (Baltimore). 94, 1-7.

Chou C-I., Shih C-J., Chen Y-T., Ou S-M., Yang C-Y., Kuo S-C. and Chu D., 2016. Adverse Effects of Oral Nonselective and cyclooxygenase- 2Selective NSAIDs on Hospitalization for Acute Kidney Injury. Medicine (Baltimore). 95, 1-5.

Chou R., Gordon DB., Leon-Casasola OA. de Rosenberg JM. and Bickler S., et al., 2016. Management of postoperative pain: A clinical practice guideline from the American pain society, the American society of regional anesthesia and pain medicine, and the American society of anesthesiologists' committee on regional anesthesia, executive commi. J. Pain 17, 131-157.

Eftekharian HR., and Pak HI., 2017. Effect of Intravenous Ketorolac on Postoperative Pain in Mandibular Fracture Surgery; A Randomized, Double-Blind, PlaceboControlled Trial. Bull. Emerg. Trauma 5, 1317.

Faught LN., Greff MJE., Rieder MJ. and Koren G., 2015. Drug-induced acute kidney injury in children. Br. J. Clin. Pharmacol. 80, 901-909.

Feldman HI., Kinman JL., Berlin JA., Hennessy S., Kimmel SE., Farrar J., Carson JL. and Strom BL., 1997. Parenteral Ketorolac: The Risk for Acute Renal Failure. Ann. Intern. Med. 126, 193-199.

Gonza'lez ELM., Patrignani P., Tacconelli S., and Rodri'guez LAG., 2010. Variability Among Nonsteroidal Antiinflammatory Drugs in Risk of Upper Gastrointestinal Bleeding. Arthritis Rheum. 62, 1592-1601.

Grosser T., Smyth EM. and FitzGerald GA., 2018. Pharmacotherapy of Inflammation, Fever, Pain, and. In: Brunton, L.L., Hilal-Dandan, R., Knollmann, B.C. (Eds.), The Goodman \& Gilman'S The Pharmacological Basis of Therapeutics. McGraw Hill, New York, pp. 687-709.

Hawker GA., Mian S., Kendzerska T. and French M., 2011. Measures of adult pain: Visual Analog 
Scale for Pain (VAS Pain), Numeric Rating Scale for Pain (NRS Pain), McGill Pain Questionnaire (MPQ), Short-Form McGill Pain Questionnaire (SF-MPQ), Chronic Pain Grade Scale (CPGS), Short Form-36 Bodily Pain Scale (SF. Arthritis Care Res. (Hoboken)). 63, S240-S252.

Ingrasciotta Y., Sultana J., Giorgianni F., Fontana A., Santangelo A. et al., 2015. Association of Individual Non-Steroidal AntiInflammatory Drugs and Chronic Kidney Disease: A Population-Based Case Control Study. PLoS One 10, e0122899.

Kementerian Kesehatan, 2016. Keputusan Menteri Kesehatan Republik Indonesia Nomor HK.02.02/Menkes/137/2016 Tentang Perubahan Atas Keputusan Menteri Kesehatan Nomor HK.02.02/Menkes/523/2015 Tentang Formularium Nasional. Kementrian Kesehatan Republik Indonesia, Indonesia.

Levey A., Greene T., Kusek J., and Beck G., 2000. A simplified equation to predict glomerular filtration rate from serum creatinine. J. Am. Soc. Nephrol. 11, 155A.

Misurac JM., Knoderer CA., Leiser JD., Nailescu C., Wilson AC. and Andreoli SP., 2013. Nonsteroidal anti-inflammatory drugs are an important cause of acute kidney injury in children. J. Pediatr. 162, 1153-1159.

Mony D., Kulkarni D. and Shetty L., 2016. Comparative Evaluation of Preemptive Analgesic Effect of Injected Intramuscular Diclofenac and Ketorolac After Third Molar Surgery-A Randomized Controlled Trial. J. Clin. Diagnostic Res. 10, ZC102-ZC106.

Mwaka G., Thikra S., and Mung'ayi V., 2013. The Prevalence of Postoperative Pain in The First 48 Hours Following Day Surgery at a Tertiary Hospital in Nairobi. Afr. Health Sci. 13, 768-776.

O'Neil CK., 2016. Pain Management. In: ChisholmBurns, M.A., Schwinghammer, T.L., Wells, B.G., Malone, P.M., Kolesar, J.M., DiPiro, J.T. (Eds.), Pharmacotherapy: Principles and
Practice. McGraw Hill, pp. 521-533.

Permata VA., 2014. Penggunaan Analgesik Pasca Operasi Orthopedi di RSUP dr. Kariadi Semarang. Universitas Diponegoro.

Rae P., Crane M. and Pattenden R., 2018. Clinical Biochemistry: Lecture Notes, 10th ed. Wiley-Blackwell.

Robleda G., Sillero-Sillero A., Puig T., Gich I. and Baños J-E., 2014. Influence of Preoperative Emotional State on Postoperative Pain Following Orthopedic and Trauma Surgery. Rev. Lat. Am. Enfermagem 22, 785-791.

Shah AV., Kumar KVA., Rai KK. and Kumar BPR., 2013. Comparative Evaluation of PreEmptive Analgesic Efficacy of Intramuscular Ketorolac Versus Tramadol Following Third Molar Surgery. J. Maxillofac. Oral Surg. 12, 197-202.

Siribumrungwong K., Cheewakidakarn J., Tangtrakulwanich B., and Nimmaanrat S., 2015. Comparing Parecoxib and Ketorolac as Preemptive Analgesia in Patients Undergoing Posterior Lumbar Spinal Fusion: A Prospective Randomized DoubleBlinded Placebo-Controlled Trial. BMC Musculoskelet. Disord. 16, 1-8.

Strom BL., Berlin JA., Kinman JL., Spitz PW., Hennessy S., Feldman H., Kimmel S. and Carson JL. 1996. Parenteral ketorolac and risk of gastrointestinal and operative site bleeding: A postmarketing surveillance study. J. Am. Med. Assoc. 275, 376-382.

Vadivelu N., Chang D., Helander EM., Bordelon GJ., Kai A. et al., 2017. Ketorolac, Oxymorphone, Tapentadol, and Tramadol: A Comprehensive Review. Anesthesiol. Clin. 35, e1-e20.

Zhang X., Donnan PT., Bell S. and Guthrie B., 2017. Non-steroidal anti-inflammatory drug induced acute kidney injury in the community dwelling general population and people with chronic kidney disease: systematic review and meta-analysis. $B M C$ Nephrol. 18, 1-12. 